\section{Uma análise da progressividade do financiamento do Sistema Único de Saúde (SUS)}

\author{
Analysis of the progressivity of Brazilian Unified \\ National Health System (SUS) financing
}

\author{
1 Escola Nacional de Saúde \\ Pública Sergio Arouca, \\ Fundação Oswaldo Cruz, \\ Rio de Janeiro, Brasil. \\ 2 Agência Nacional \\ de Saúde Suplementar, \\ Rio de Janeiro, Brasil. \\ Correspondência \\ M. A. D. Ugá \\ Departamento de \\ Administração e \\ Planejamento em Saúde, \\ Escola Nacional de Saúde \\ Pública Sergio Arouca, \\ Fundação Oswaldo Cruz. \\ Rua Leopoldo Bulhões 1480, \\ Rio de Janeiro, $R J$ \\ 21041-210, Brasil. \\ domingue@ensp.fiocruz.br
}

\begin{abstract}
This article analyzes the level of progressivity in taxes financing the Brazilian Unified National Health System (SUS). Distribution of the tax burden financing the SUS was calculated using micro-data from the Household Budgets Survey, 2002-2003. The Kakwani index, which shows a tax system's level of progressivity, was calculated. The Kakwani index of public financing was -0.008, and SUS financing was nearly proportional to income. From a social justice perspective this is highly undesirable in a society like Brazil, with a Gini index of 0.57. The system should be clearly progressive in order to counterbalance the country's extreme income concentration.
\end{abstract}

SUS (BR); Health Financing; Government Financing
Maria Alicia Domínguez Ugá ${ }^{1}$

Isabela Soares Santos 2

\section{Apresentação}

Este artigo analisa o grau de progressividade (ou regressividade) dos tributos que financiam o Sistema Único de Saúde (SUS). Tratando-se de um sistema de saúde inserido em um sistema de seguridade social inspirado nos padrões welfarianos, em que o acesso esteja definido pela necessidade e não pela capacidade de pagamento, é desejável que o financiamento setorial seja um sistema pautado pela progressividade, isto é, que penalize mais do que proporcionalmente aqueles que mais têm ou, em outras palavras, que o ônus do financiamento do setor saúde seja inversamente proporcional à renda das pessoas.

Neste artigo são identificados os principais tributos que financiam o SUS e, a partir dos microdados da Pesquisa de Orçamentos Familiares, POF/IBGE 2002-2003 (disponível em: http://www.ibge.gov.br) - que exibem os pagamentos efetuados e a cesta de consumo sobre a qual incidem os tributos indiretos - é inferida a distribuição do ônus do pagamento dos tributos diretos e indiretos que financiam o SUS e, ainda, analisado o grau de progressividade dos mesmos. 


\section{A estrutura do financiamento do sistema de saúde brasileiro}

A instituição do acesso universal à saúde, enquanto um direito inerente à cidadania, foi coerentemente acompanhada da inserção do Setor Saúde no Sistema de Seguridade Social e, ainda, do financiamento setorial por meio do Orçamento da Seguridade Social (OSS) e dos Tesouros Federal, Estaduais e Municipais.

A composição do OSS - sem vincular fontes para cada área específica - contemplou a natureza distinta dos benefícios e serviços por ele financiados: (i) os de caráter contributivo e individualizados (tais como os do regime geral de aposentadorias) e (ii) os benefícios regidos pela lógica da cidadania (tais como o acesso universal à saúde e o "salário cidadão" de um salário mínimo para a população de mais de 65 anos ou portadora de deficiência); assim, foram contempladas tanto as tradicionais contribuições sobre a folha de salários (da empresa e do trabalhador), como as contribuições sobre o lucro líquido (CSLL) e sobre o faturamento (COFINS) e, ainda, previu-se o ingresso ao OSS dos recursos do Tesouro que se fizessem necessários para atender as necessidades decorrentes desse modelo de proteção social welfariano.

Dessa forma, por um lado, incorporaram-se fontes novas (tais como a CSLL) e, por outro, ampliou-se a base de incidência de tributos já existentes (como a do antigo FINSOCIAL, atual COFINS) e, ainda, previu-se a participação de receita fiscal no financiamento do sistema, de forma tal a garantir a sua viabilização. Ressaltase que ao se constituir um orçamento unificado pretendeu-se racionalizar a alocação de recursos do OSS, evitando a pulverização no uso de receitas de fundos previamente existentes.

Por meio de lei complementar, dispôs-se que $30 \%$ dos recursos do OSS, que são de origem federal, deveriam ser destinados ao SUS e que a estes deveriam ser acrescidas, segundo a Constituição da República Federativa do Brasil, receitas provenientes dos Tesouros Estaduais e Municipais, que viabilizassem a implementação desse sistema.

Entretanto, alguns desvios em relação aos preceitos constitucionais que regem o financiamento da seguridade social e, ainda, problemas específicos do financiamento do setor saúde frente ao ajuste fiscal 1,2 fizeram com que $o$ Ministério da Saúde tivesse de enfrentar penoso processo no Congresso Nacional para aprovar um tributo adicional, vinculado à saúde: a instituição do Imposto Provisório sobre Movimentação Financeira (IPMF), que passou a vigorar em 23 de janeiro de 1997 (hoje CPMF -
Contribuição Provisória sobre Movimentação Financeira), com vigência temporária de um ano, mas renovada sucessivamente desde 1998.

Note-se que, em que pese o fato de o Ministério da Saúde haver tido de recorrer à introdução de nova contribuição específica (a CPMF) para solucionar o problema do financiamento setorial, este problema encontra suas raízes fora do setor saúde e externamente ao OSS, posto que as sucessivas necessidades de financiamento enfrentadas pelas áreas que compõem a Seguridade Social se deram, fundamentalmente, porque: (i) não entram no OSS a totalidade dos recursos que lhe pertencem; (ii) os recursos que ingressam no OSS não o fazem com a devida regularidade; e, finalmente, (iii) são pagos com recursos do OSS gastos que não correspondem às atividades específicas da seguridade social 1 .

\section{A participação do setor público}

Correspondendo à estrutura herdada do modelo do sistema de saúde prévio ao SUS, no qual o papel do Estado havia sido fundamentalmente o de promover a expansão do setor privado, a estrutura do gasto nacional em saúde também está fortemente marcada por essa herança. Assim, nosso sistema de saúde, constitucionalmente definido como sendo de acesso universal e integral, exibe uma estrutura do gasto muito diferente da dos sistemas nacionais de saúde de cunho welfariano, pois no Brasil a participação do setor público no gasto nacional em saúde é de apenas $44 \%$ - sendo, portanto, igual à norte-americana, de $44 \%$, cujo sistema de saúde é tido como padrão do modelo liberal.

A Tabela 1 mostra a composição do financiamento setorial no Brasil e revela que o setor privado ainda participa em $56 \%$ do gasto em saúde, e na participação do setor privado do gasto em saúde, o gasto direto das famílias (principalmente em medicamentos) é ainda hoje grande, em que pesem os avanços do SUS.

É ainda baixa, portanto, a participação do gasto público no sistema de saúde brasileiro, tendo em vista os princípios da universalidade e da integralidade do acesso à atenção à saúde que norteiam o SUS.

\section{A participação das três esferas de governo no gasto público em saúde}

Até meados da década de noventa, o gasto público em saúde guardava a marca do período anterior à nova Constituição da República Federativa do Brasil, caracterizado por uma forte 
centralização do sistema de saúde e do seu financiamento em nível federal. Assim, a partir do processo de descentralização tributária introduzido pela nova Carta Constitucional - que ampliou a competência tributária de estados e municípios e elevou o nível das transferências de tributos federais às esferas infranacionais de governo - e da Emenda Constitucional n. 293 que estabelece porcentuais mínimos de participação das receitas próprias dos estados e municípios no financiamento do SUS, se observa uma progressiva descentralização do financiamento do SUS.

Em 1993 os municípios adquirem um protagonismo maior no financiamento, coerente com o caráter inicialmente municipalista do SUS e, em 2002, a esfera estadual de governo passa a participar de forma muito mais ativa, fruto tanto do resgate do seu papel de gestor do SUS através da Norma Operacional Básica do SUS (NOB-96) e da Norma Operacional de Assistência à Saúde (NOAS), como da regulação estabelecida por meio da Emenda Constitucional n. 29. Em 2002 os municípios já estavam assumindo $22 \%$ do gasto público em saúde e os estados aportaram $20 \%$ do mesmo (Tabela 2).

É importante observar que o processo de descentralização tributária verificado a partir da nova Carta Constitucional não só ampliou a competência tributária de estados e municípios como elevou o nível das transferências de tributos federais às esferas subnacionais de governo. Assim, a partir da reforma tributária introduzida na Constituição da República Federativa do Brasil de 1988, competem aos estados os seguintes tributos: (i) o Imposto sobre Operações Relativas à Circulação de Mercadorias e Prestação de Serviços de Transporte Interestadual e de Comunicação (ICMS); (ii) o Imposto sobre Transmissão "Causa Mortis" e Doação de Bens e Direitos (ITCMD); (iii) o Imposto sobre a Propriedade de Veículos Automotores (IPVA) e; (iv) $5 \%$ adicionais ao Imposto de Renda (IR) incidente sobre rendimentos de capital - inclusive lucros - devido à União.

Além desses impostos próprios, os estados viram-se beneficiados com um aumento das transferências constitucionais diretas de tributos federais, pelo Fundo de Participação dos Estados (FPE), que passou a receber $21,5 \%$ do IR e do Imposto sobre Produtos Industrializados (IPI) arrecadados pela União - em vez de $14 \%$, como fazia antes de 1988 -; ainda, $10 \%$ dos recursos do IPI passaram a ser redistribuídos àqueles estados que exportam produtos industriais, proporcionalmente ao valor dessas exportações. Por outro lado, no que concerne a estados de regiões pobres, beneficiários do Fun-
Tabela 1

Composição do gasto em saúde. Brasil, 2002

\begin{tabular}{lrr}
\hline Gasto em saúde & R\$ (milhões) & $\%$ \\
\hline Gasto público total & $50.473,5$ & 43,8 \\
Gasto privado (planos e seguros de saúde) & $25.063,1$ & 21,7 \\
Gasto privado direto das famílias & $39.778,5$ & 34,5 \\
Gasto total & $115.315,1$ & 100,0 \\
\hline
\end{tabular}

Fonte: elaboração própria, com base em dados da Pesquisa de Orçamentos Familiares (POF/IBGE 2002-2003), do Sistema de Informações sobre Orçamentos Públicos em Saúde (SIOPS) e da Agência Nacional de Saúde (ANS).

Tabela 2

Participação das esferas de governo no gasto público em saúde. Brasil, 1980-2002.

\begin{tabular}{lccccc}
\hline Esfera & $\mathbf{1 9 8 0}(\%)$ & $\mathbf{1 9 9 0}(\%)$ & $\mathbf{1 9 9 2}(\%)$ & $\mathbf{1 9 9 3}(\%)$ & $\mathbf{2 0 0 2}(\%)^{\star}$ \\
\hline Federal & 75 & 73 & 68 & 72 & 58 \\
Estadual & 18 & 15 & 14 & 12 & 20 \\
Municipal & 7 & 12 & 18 & 16 & 22 \\
\hline
\end{tabular}

* Elaboração própria com base em dados do Sistema de Informações sobre Orçamentos Públicos em Saúde (SIOPS).

Fonte: Médici 14

do Especial para Fomento às Regiões Pobres, passaram a receber através dos bancos regionais de desenvolvimento $4 \%$ (em vez de $3 \%$ ) da arrecadação do IPI e do IR.

Note-se que essas transferências automáticas e diretas efetuadas pelo FPE têm forte caráter redistributivo, uma vez que o montante referente a cada Unidade da Federação é diretamente proporcional à respectiva população e inversamente proporcional à renda da mesma.

Entretanto, tendo em vista o aumento das transferências de estados aos municípios (explicitado a seguir), a disponibilidade final de recursos dos estados manteve-se praticamente igual (absorvendo em torno de $26 \%$ da arrecadação tributária global), sendo, portanto, os municípios os que mais ganharam com a reforma tributária.

Efetivamente, os municípios mantiveram o Imposto sobre a Propriedade Predial e Territorial Urbana (IPTU) e o Imposto sobre Serviços de Qualquer Natureza (ISS), e obtiveram com a reforma tributária dois novos tributos: o Imposto sobre Venda de Combustíveis a Varejo (IVCV) e o Imposto sobre Transmissão Intervivos de Bens e Direitos sobre Imóveis (ITBI). 
Mas é do aumento das transferências federais e estaduais que advém a maior parte dos ganhos tributários das esferas locais de governo: (i) eles passaram a absorver, por meio do Fundo de Participação dos Municípios (FPM) $22,5 \%$ (em vez de $17 \%$ ) do IPI e do IR; (ii) a União passou a transferir-lhes $50 \%$ da arrecadação do Imposto Territorial Rural (ITR); (iii) os estados passaram a transferir aos municípios $25 \%$ (em vez de $20 \%$ ) da sua arrecadação de ICMS e, ainda, $50 \%$ do valor do IPVA arrecadado. Dessa forma, as esferas locais de governo passaram a reter $34 \%$ da carga tributária global brasileira 4

Deve-se mencionar, entretanto, que esses ganhos das esferas estadual e municipal viramse afetados pelo Fundo Social de Emergência, criado em 1994 e depois renomeado como Fundo de Estabilização Fiscal em 1997 e atualmente denominado Desvinculação das Receitas da União (DRU - em 2000), dado que $20 \%$ das receitas de impostos e contribuições passaram a ser retidos e livremente alocados pelo governo federal, inclusive para pagamento dos juros da dívida $1,5,6$, com o qual as transferências do governo federal referentes ao FPE e ao FPM foram severamente atingidas, uma vez que elas advêm da arrecadação do IR e do IPI.

\section{Metodologia: fontes e tratamento dos dados}

A consolidação da distribuição do ônus do financiamento público e privado do sistema de saúde brasileiro foi realizada com base nos microdados da POF/IBGE 2002-2003.

No que tange à estrutura tributária, foram utilizados dados do Banco Nacional de Desenvolvimento Econômico e Social (BNDES) e para o financiamento de 2002 do SUS, dados do Instituto de Pesquisa Econômica Aplicada (IPEA) e do Sistema de Informações sobre Orçamentos Públicos em Saúde (SIOPS).

\section{Variável renda}

O conceito de renda bruta da POF/IBGE 20022003 engloba todos os recebimentos da família, monetários e não monetários, sendo os rendimentos monetários aqueles provenientes do trabalho, as transferências, os de aluguel e outros rendimentos - por exemplo vendas esporádicas, empréstimos e aplicações de capital. Os não monetários dizem respeito às coisas que são produzidas, à pesca, a recebimentos e trocas em bens - escambo - durante o período de referência da pesquisa.

\section{Variável despesa}

Na variável despesa tomaram-se aquelas classificadas como "Despesas Correntes" das famílias pela POF/IBGE 2002-2003, que considera as realizadas com alimentação, habitação, vestuário, transporte, higiene e cuidados pessoais, assistência à saúde, educação, recreação e cultura, fumo, serviços pessoais, despesas diversas e outras despesas correntes. Esta informação foi utilizada para estimar o financiamento público do setor saúde, em especial dos tributos indiretos conforme explicitado adiante.

\section{Tributos que financiam o Sistema} Único de Saúde (SUS)

Foram gerados os resultados da distribuição da carga tributária relativa à parcela dos impostos e contribuições sociais que financiam o SUS, segundo decis de renda, sendo o ano de 2002 o período de referência para a estrutura do financiamento do setor público de saúde e para a definição das alíquotas dos tributos.

Entre os tributos considerados para estimar a despesa familiar que se refere à parcela de tributos que financiaram o SUS estão COFINS, CPMF, IPI, ICMS, ISS, Imposto de Renda Pessoa Física (IRPF), IPTU e IPVA, que são responsáveis por $70 \%$ do financiamento público do sistema de saúde (conforme Tabela 3).

\section{- Tributos diretos}

Os tributos diretos que têm maior peso no financiamento setorial são o IRPF, IPVA, IPTU e parte da CPMF.

As variáveis dos pagamentos com os tributos IPVA e IPTU foram apuradas nos microdados da POF/IBGE 2002-2003 e se mostraram consistentes, tendo sido consideradas nos cálculos do financiamento do SUS.

Para mensurar os valores dos pagamentos realizados com IRPF por nível de renda, utilizou-se um estudo de Siqueira et al. 7, realizado com base na Pesquisa Nacional por Amostra Domiciliar (PNAD/IBGE) de 1999 e que simulou os pagamentos do IRPF baseando-se nos dados individuais.

A parte da arrecadação da CPMF que incide sobre as transações financeiras das famílias foi considerada tributo direto, mas a que incide sobre pessoas jurídicas foi tratada como indireto. Para calcular a parte direta, primeiramente foi calculada a indireta e, uma vez identificada qual a parcela cumulativa deste tributo embutida nos preços finais dos produtos, foi estimada, por resíduo, a parcela da arrecadação total que 
Composição do financiamento do sistema de saúde (em milhões de Reais correntes). Brasil, 2002

\begin{tabular}{|c|c|c|c|c|c|c|c|}
\hline $\begin{array}{l}\text { Itens por esfera } \\
\text { de governo } \\
\text { à saúde* }\end{array}$ & $\begin{array}{l}\text { Receita - } \\
\text { tributos } \\
\text { (BNDES) }\end{array}$ & $\begin{array}{l}\text { Receita - } \\
\text { tributos } \\
\text { (SIOPS) }\end{array}$ & $\begin{array}{l}\text { Recursos } \\
\text { destinados } \\
\text { à saúde* }\end{array}$ & $\begin{array}{l}\text { Recursos } \\
\text { destinados } \\
\text { à saúde } \\
\text { (\% por esfera } \\
\text { de governo) }\end{array}$ & $\begin{array}{l}\text { Recursos } \\
\text { destinados } \\
\text { à saúde } \\
\text { (\% da recita } \\
\text { tributária) }\end{array}$ & $\begin{array}{l}\text { Recursos } \\
\text { destinados } \\
\text { à saúde } \\
\text { (\% do público) }\end{array}$ & $\begin{array}{l}\text { Recursos } \\
\text { destinados } \\
\text { à saúde } \\
\text { (\% do total do } \\
\text { financiamento) }\end{array}$ \\
\hline \multicolumn{8}{|l|}{ União } \\
\hline COFINS & $50.856,00$ & & $4.455,80$ & 15,20 & 8,76 & 8,83 & 3,86 \\
\hline CPMF & $20.267,00$ & & $11.982,40$ & 40,80 & 59,12 & 23,74 & 10,39 \\
\hline Demais fontes & $193.263,00$ & & $5.323,10$ & 18,10 & 2,75 & 10,55 & 4,62 \\
\hline $\mid \mathrm{PI}$ & $18.472,00$ & & & & & & \\
\hline IR & $75.551,00$ & & & & & & \\
\hline $\begin{array}{l}\text { Subtotal (receita } \\
\text { disponível) }\end{array}$ & $276.761,00$ & & $29.341,10$ & 100,00 & 10,60 & 58,13 & 25,44 \\
\hline $\begin{array}{l}\text { Estados (despesa } \\
\text { saúde: } 8,82 \% \text { da } \\
\text { receita disponível) }\end{array}$ & & & & & & & 0,00 \\
\hline $\begin{array}{l}\text { ICMS (total: } 25 \% \\
\text { sobre transferência } \\
\text { a municípios) }\end{array}$ & $81.032,50$ & & & & & & \\
\hline $\begin{array}{l}\text { ICMS (total: } 25 \% \\
\text { sobre transferência } \\
\text { a municípios) }\end{array}$ & & $77.196,90$ & $6.808,80$ & 67,00 & 6,61 & 13,49 & \\
\hline $\begin{array}{l}\text { IPVA (total: } 50 \% \\
\text { sobre transferência } \\
\text { a municípios) }\end{array}$ & $3.472,40$ & $3.472,40$ & 306,30 & 3,00 & 4,41 & 0,61 & 0,27 \\
\hline Demais fontes & $15.362,80$ & & & & & & 0,00 \\
\hline $\begin{array}{l}\text { Transferido } \\
\text { da União }\end{array}$ & $27.813,40$ & & & & & & 0,00 \\
\hline $\begin{array}{l}\text { Cota parte FPE } \\
(21,5 \% \text { sobre } \\
\text { IR + IPI) }\end{array}$ & $17.742,60$ & $20.876,30$ & $1.841,30$ & 18,10 & & 3,65 & 1,60 \\
\hline $\mid \mathrm{PI}$ & & & 360,90 & 3,60 & 1,95 & 0,72 & 0,31 \\
\hline IR & $81.032,50$ & & $1.480,40$ & 14,60 & 1,96 & 2,93 & 1,28 \\
\hline Outras & $10.070,80$ & & & & & & 0,00 \\
\hline $\begin{array}{l}\text { Subtotal (receita } \\
\text { disponível) }\end{array}$ & $120.213,20$ & $14.918,70$ & $10.163,70$ & 100,00 & & 20,14 & 8,81 \\
\hline \multicolumn{8}{|l|}{$\begin{array}{l}\text { Municípios (despesa } \\
\text { saúde: } 15,4 \% \text { da } \\
\text { receita disponível) }\end{array}$} \\
\hline ISS & $7.359,90$ & $8.064,00$ & $1.241,90$ & 11,30 & 16,87 & 2,46 & 1,08 \\
\hline IPTU & $6.203,20$ & $6.748,90$ & $1.039,30$ & 9,50 & 16,75 & 20,60 & 0,90 \\
\hline ITBI & $1.331,70$ & $1.457,80$ & 224,50 & 2,00 & 16,86 & 0,44 & 0,19 \\
\hline Demais fontes & $7.669,70$ & & & & & & 0,00 \\
\hline
\end{tabular}

(continua) 


\begin{tabular}{|c|c|c|c|c|c|c|c|}
\hline $\begin{array}{l}\text { Itens por esfera } \\
\text { de governo } \\
\text { à saúde* }\end{array}$ & $\begin{array}{l}\text { Receita - } \\
\text { tributos } \\
\text { (BNDES) }\end{array}$ & $\begin{array}{l}\text { Receita - } \\
\text { tributos } \\
\text { (SIOPS) }\end{array}$ & $\begin{array}{l}\text { Recursos } \\
\text { destinados } \\
\text { à saúde }\end{array}$ & $\begin{array}{l}\text { Recursos } \\
\text { destinados } \\
\text { à saúde } \\
\text { (\% por esfera } \\
\text { de governo) }\end{array}$ & $\begin{array}{l}\text { Recursos } \\
\text { destinados } \\
\text { à saúde } \\
\text { (\% da recita } \\
\text { tributária) }\end{array}$ & $\begin{array}{l}\text { Recursos } \\
\text { destinados } \\
\text { à saúde } \\
\text { (\% do público) }\end{array}$ & $\begin{array}{l}\text { Recursos } \\
\text { destinados } \\
\text { à saúde } \\
\text { (\% do total do } \\
\text { financiamento) }\end{array}$ \\
\hline \multicolumn{8}{|l|}{ Transferências } \\
\hline Federais & $23.686,70$ & & & & & & 0,00 \\
\hline $\begin{array}{l}\text { FPM }(22,5 \% \\
\text { sobre IR + IPI) }\end{array}$ & $18.594,70$ & $19.524,10$ & $3.006,70$ & 27,40 & & 5,96 & 2,61 \\
\hline IPI & & & 589,30 & 5,40 & 3,19 & 1,17 & 0,51 \\
\hline IR & & & $2.417,40$ & 22,00 & 3,20 & 4,79 & 2,10 \\
\hline ITR & 121,50 & & & & & & 0,00 \\
\hline Outras & $4.970,50$ & & & & & & 0,00 \\
\hline Estaduais & $32.859,40$ & & & & & & 0,00 \\
\hline IPVA (50\%) & $3.472,40$ & $3.472,40$ & 534,70 & 4,90 & 7,70 & 1,06 & 0,46 \\
\hline ICMS (25\%) & $21.919,10$ & $25.732,30$ & $3.962,80$ & 36,10 & 3,85 & 7,85 & 3,44 \\
\hline Outras & $7.467,90$ & & & & & & 0,00 \\
\hline $\begin{array}{l}\text { Subtotal (receita } \\
\text { disponível) }\end{array}$ & $79.110,80$ & $71.193,90$ & $10.968,70$ & 100,00 & & 21,73 & 9,51 \\
\hline Total público & $476.085,00$ & & $50.473,50$ & & 10,60 & 100,00 & 43,77 \\
\hline $\begin{array}{l}\text { Gasto privado } \\
\text { direto das famílias } \\
\text { (excluindo os } \\
\text { gatos com planos } \\
\text { de saúde) }\end{array}$ & & & $39.778,50$ & & & & 34,50 \\
\hline $\begin{array}{l}\text { Gasto privado com } \\
\text { planos e seguros } \\
\text { de saúde }\end{array}$ & & & $25.063,10$ & & & & 21,73 \\
\hline Total & & & $115.315,10$ & & & & 100,00 \\
\hline
\end{tabular}

* Fontes públicas: União - dados calculados pelo Instituto de Pesquisa Econômica Aplicada (IPEA) com base no Sistema Integrado de Dados Orçamentários (SIDOR) e Sistema Integrado de Administração Financeira (SIAFI);

Estados - estimados pela equipe Sistema de Informações sobre Orçamentos Públicos em Saúde (SIOPS) com base nos Balanços Estaduais,

e Municípios - dados informados até 17 de dezembro de 2003 ao SIOPS por 4.770 municípios que representam $93 \%$ da população.

** Fonte: Pesquisa de Orçamentos Familiares (POF/IBGE 2002-2003), gastos privados com saúde subtraídos os gastos declarados

no item planos e seguros de saúde

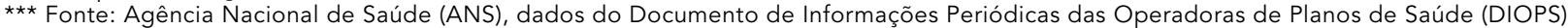

ano base 2003. Contempla o financiamento efetuado por pessoas físicas e pessoas jurídicas.

representa a modalidade direta. Assim, a parte direta da CPMF foi calculada junto com a estimativa da cumulatividade dos tributos indiretos e incluída diretamente na matriz insumoproduto elaborada para o cálculo final da cumulatividade dos tributos (ver mais detalhes no próximo item, referente aos tributos indiretos).

\section{- Tributos indiretos}

Para os tributos indiretos (IPI, ICMS, ISS, COFINS e parte da CPMF), que incidem sobre as várias fases de produção e comercialização de serviços e produtos, adotou-se metodologia desenvolvida por Pereira \& Ikeda 8, em que são consideradas as características do processo de produção de cada produto para estimar as cadeias de tributação acumuladas, até a etapa do consumo final. A aplicação das alíquotas dos tributos utilizados foi feita respeitando-se as regras de cada tributo definidas na legislação do período de competência (2002).

Ainda, o consumo das famílias foi identificado por meio da POF/IBGE disponível na época (isto é, a versão de 1995-1996) e justaposto à matriz insumo-produto para o cálculo da contribuição de cada classe de renda familiar sobre o financiamento dos tributos indiretos.

O resultado é o peso que cada tributo indireto tem sobre a renda familiar. Este dado foi estimado por classe de renda de salário mínimo, considerando as utilizadas nas publica- 
ções oficiais da POF/IBGE (até 2 salários mínimos, mais de 2 a 5 salários mínimos, mais de 5 a 10 salários mínimos, mais de 10 a 20 salários mínimos e acima de 20 salários mínimos).

\section{Aplicação dos pesos dos tributos}

Pelas despesas da cesta de consumo familiar foi identificado o peso do financiamento de cada tributo em cada classe de renda (em salário mínimo) e este foi multiplicado ao peso que a participação do tributo no financiamento do setor público de saúde tem em relação à arrecadação total do tributo. Este peso foi aplicado à renda de cada família, de acordo com a classificação de sua renda na POF/IBGE 2002-2003.

Para cada registro de família da amostra da POF/IBGE 2002-2003 foram atribuídos dois pesos: um da representatividade que cada registro de família da amostra possui em relação ao universo da população que ela representa, e outro estimando a quantidade de pessoas com poder de contribuição em cada família, resultando em dados familiares per capita. Foi adotado para isso o fator médio utilizado nas aplicações da metodologia de Wagstaff \& van Doorslaer 9,10, 11,12,13 de análise da eqüidade do financiamento. Portanto os dados das receitas e despesas familiares foram equalizados em receitas e despesas familiares per capita, obtidos pela aplicação do exponencial 0,75.

\section{Resultados}

Os resultados mostram que as despesas inerentes ao financiamento do sistema de saúde brasileiro absorvem $9,7 \%$ da renda das famílias. Como se observa na Figura 1 e na Tabela 4 abaixo, o ônus do financiamento setorial e a participação de cada tipo de gasto em saúde varia consideravelmente, segundo decis de renda.

Enquanto para o primeiro decil da população, ordenada por sua renda familiar per capi$t a$, os gastos em saúde absorvem mais de dez por cento $(10,6 \%)$ da mesma; no que se refere ao último décimo populacional este porcentual diminui para 9,1\%. Chama a atenção, ainda, o peso do gasto privado direto sobre as famílias mais pobres: este gasto - que, por definição, é catastrófico, não decorrente de uma escolha e sim de uma necessidade - representa $6,8 \%$ da renda das famílias do primeiro décimo e sua participação é inversamente proporcional à renda, diminuindo nos decis superiores, representando apenas $3,1 \%$ da renda do último decil.

A curva de Lorenz brasileira, apresentada na Figura 2, evidencia o já conhecido elevadíssimo grau de concentração da renda no nosso país. Corresponde-lhe um índice de Gini de 0,57, muitíssimo mais elevado que o dos países desenvolvidos e, também, que o dos demais

Figura 1

Peso do financiamento do setor saúde sobre a renda familiar per capita, segundo tipo de gasto, por decil de renda per capita. Brasil, 2002.

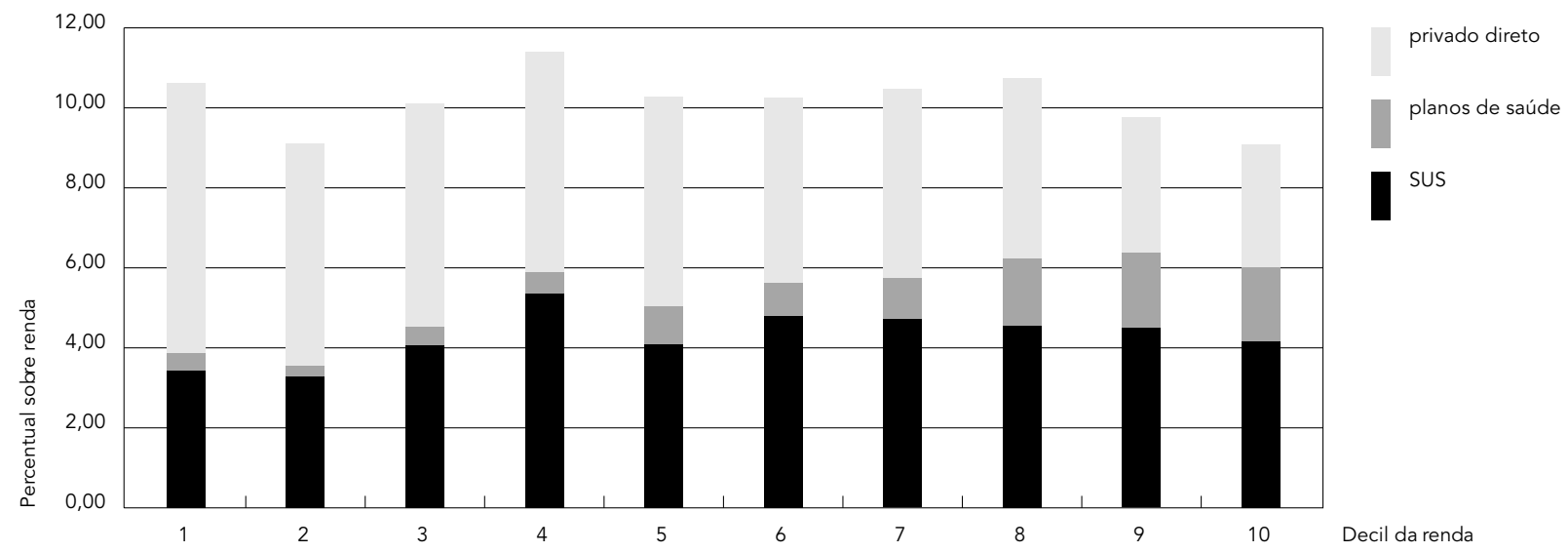

Fonte: Pesquisa de Orçamentos Familiares (POF/IBGE 2002-2003), do Sistema de Informações sobre Orçamentos Públicos em Saúde (SIOPS). 
Tabela 4

Distribuição do peso do financiamento do Sistema Único de Saúde (SUS), segundo decil de renda. Brasil, 2002

\begin{tabular}{crcc}
\hline Decil de renda & Renda (\%) & \multicolumn{2}{c}{ Financiamento do SUS } \\
& & \multicolumn{1}{c}{$\%$} & \begin{tabular}{c} 
Peso na renda \\
\hline 1
\end{tabular} \\
2 & 1,00 & 0,78 & 3,42 \\
3 & 1,92 & 1,45 & 3,28 \\
4 & 2,74 & 2,56 & 4,06 \\
5 & 3,56 & 4,39 & 5,34 \\
6 & 4,53 & 4,26 & 4,08 \\
7 & 5,80 & 6,40 & 4,78 \\
8 & 7,59 & 8,23 & 4,70 \\
9 & 10,43 & 10,93 & 4,54 \\
10 & 16,34 & 16,89 & 4,48 \\
Total & 46,10 & 44,11 & 4,15 \\
\hline
\end{tabular}

Fonte: elaboração própria, com base em dados da Pesquisa de Orçamentos Familiares (POF/IBGE 2002-2003), do Sistema de Informações sobre Orçamentos Públicos em Saúde (SIOPS). concerne ao privilégio do décimo de renda mais rico e proporcional em relação aos estratos da população pertencentes do 4o ao 9o décimos - que correspondem à população de renda baixa e média baixa.

O grau de progressividade de cada tributo que financia o SUS é inferido por meio da Tabela 5 , que evidencia a já esperada regressividade dos seguintes tributos indiretos: COFINS, IPI, ICMS e ISS.

Assim, no que diz respeito ao primeiro, vale lembrar que a COFINS incide sobre o faturamento das empresas e é facilmente transferível ao consumidor final, inserida no preço dos bens e serviços comercializados, nas diferentes etapas do processo de produção e circulação das mercadorias. Dessa forma, ao ser transferido aos preços finais, espera-se que esse tributo seja regressivo, uma vez que ele incide sobre o consumo, e não sobre a renda e/ou propriedade das pessoas.

Efetivamente, verifica-se que os oito primeiros décimos de renda concentram, nos seus aportes para a COFINS, uma porcentagem maior (ou igual, no caso do quarto decil) da renda que detêm. Correspondentemente a essa situação de regressividade, o decil de mais alta renda, que detém $46,1 \%$ da renda, concentra apenas $40,7 \%$ do pagamento. Note-se que o 9o decil, que concentra $16,3 \%$ da renda, aporta de forma proporcional $(16,1 \%)$ para esse tributo.

O mesmo fenômeno ocorre com o IPI (que integra o financiamento setorial pelas transferências intergovernamentais concernentes ao FPE e ao FPM) e com o ISS, tributo que incide sobre a venda de serviços. A regressividade dos impostos indiretos IPI e ISS, que também são transferidos aos preços, é ainda mais acentuada que a da COFINS, tendo em vista que penalizam mais fortemente os decis de renda menor e, conseqüentemente, fazem com que, enquanto o decil mais pobre detém apenas $1 \%$ da renda e efetua $1,4 \%$ dos pagamentos desses impostos, o decil mais rico concentra $46,1 \%$ da renda e responsabiliza-se por apenas $38,1 \%$ dos pagamentos, muito menos que proporcionalmente, portanto. Note-se que, do 1 o até o $8 \underline{0}$ decis, a população é penalizada mais do que proporcionalmente à renda que concentra.

No que tange ao ICMS, de competência estadual, mas também usado no financiamento municipal (dado que parte dele é transferida pelos estados aos municípios), ele é, por definição, um tributo indireto, que incide sobre o valor dos bens e serviços comercializados. Como as classes de menor renda a utilizam integralmente - ou preponderantemente - em gasto concernente ao consumo e nada ou quase 
Distribuição de renda familiar per capita segundo a Pesquisa de Orçamentos Familiares (POF/IBGE 2002-2003). Brasil, 2002.

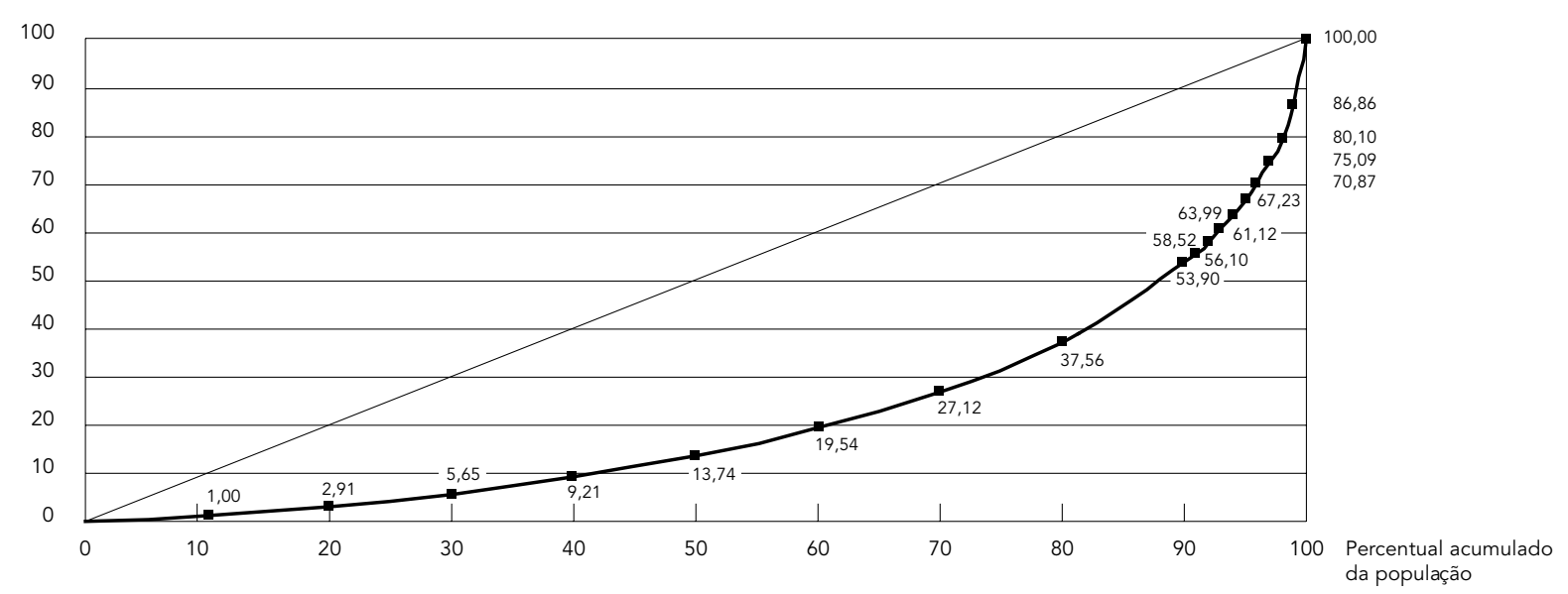

Fonte: Pesquisa de Orçamentos Familiares (POF/IBGE 2002-2003).

nada poupam, diferentemente das classes mais abastadas, é esperado que uma maior parcela da renda dos segmentos mais pobres seja absorvida pelo pagamento desse tributo. Isso é confirmado pela Tabela 5, o que evidencia que este é o mais regressivo dos tributos.

Assim, o decil inferior, retendo $1 \%$ da renda, absorve $1,36 \%$ do pagamento desse tributo. O segundo decil detém $1,92 \%$ da renda e concentra $2,55 \%$ do pagamento do ICMS. Essa relação renda/pagamento do tributo penaliza os segmentos da população pertencentes até o oitavo decil de renda, inclusive. O 9o décimo paga uma porcentagem do total do ICMS recolhido que é proporcional à sua renda, sendo o decil mais rico o grande beneficiário na arrecadação desse imposto, tendo em vista que ele retém $46,1 \%$ da renda, mas concentra apenas $38,9 \%$ do pagamento de ICMS.

A análise que segue diz respeito aos tributos diretos: IRPF, IPVA, IPTU e, em certa medida, a CPMF.

Neste estudo, tendo em vista que os dados processados provêm dos orçamentos familiares, trabalhou-se apenas com o IRPF. Os dados evidenciam a progressividade do IRPF: tendo em vista a enorme concentração de renda da sociedade brasileira, os cinco primeiros decis nada pagam desse imposto, enquanto o decil mais rico paga, mais do que proporcionalmente à sua renda, esse imposto: esse décimo da população concentra $46,1 \%$ da renda e partici- pa com a maior parte $(87,3 \%)$ do pagamento do IRPF. Note-se que ao interior desse último decil também se verifica a progressividade desse tributo, na medida em que ele penaliza mais do que proporcionalmente à renda o percentil mais rico.

No que diz respeito ao IPVA, que também é um imposto direto por incidir sobre a propriedade de bens (automotores), é evidente a sua progressividade. A parcela dos dez por cento mais ricos da população detém $46,1 \%$ da renda e concentra $53,3 \%$ do pagamento desse imposto; da mesma forma, o segundo décimo mais rico, que absorve $16,3 \%$ da renda, se responsabiliza por $21,1 \%$ do aporte desse tributo. A progressividade do IPVA diminui, entretanto, quando analisada no interior do último décimo de renda: enquanto o percentil mais rico detém $13,1 \%$ da renda da sociedade brasileira, concentra apenas $9,6 \%$ do IPVA pago. Correspondentemente a essa regressividade do IPVA observada no seio do último décimo, do 91a ao 99o centésimos pagam esse imposto mais que proporcionalmente à sua renda. Isso se deve, provavelmente, à linha do consumo saciado de bens automotores, que parece situar-se no nível de consumo efetuado pelo último percentil.

No que concerne à CPMF paga por pessoas físicas, a princípio tenderia a ser um tributo proporcional, uma vez que, incidindo sobre movimentações financeiras, penalizaria os contribuintes de forma aproximadamente propor- 
Distribuição da renda e dos pagamentos dos tributos concernentes ao financiamento do Sistema Único de Saúde (SUS), por decil de renda. Brasil, 2002.

\begin{tabular}{|c|c|c|c|c|c|c|c|c|c|}
\hline $\begin{array}{l}\text { Decil de renda } \\
\text { familiar }\end{array}$ & $\begin{array}{l}\text { Renda } \\
(\%)\end{array}$ & $\begin{array}{l}\text { COFINS } \\
(\%)\end{array}$ & $\begin{array}{l}\text { CPMF } \\
(\%)\end{array}$ & $\begin{array}{l}\text { ICMS } \\
(\%)\end{array}$ & $\begin{array}{l}\text { IPI } \\
\text { (\%) }\end{array}$ & $\begin{array}{l}\text { IRPF } \\
(\%)\end{array}$ & $\begin{array}{l}\text { IPVA } \\
(\%)\end{array}$ & $\begin{array}{l}\text { ISS } \\
\text { (\%) }\end{array}$ & $\begin{array}{l}\text { IPTU } \\
(\%)\end{array}$ \\
\hline 1 & 1,00 & 1,26 & 0,40 & 1,36 & 1,37 & - & 0,31 & 1,37 & 1,19 \\
\hline 2 & 1,92 & 2,40 & 1,65 & 2,55 & 2,57 & - & 0,60 & 2,57 & 0,86 \\
\hline 3 & 2,74 & 3,41 & 2,84 & 3,60 & 3,61 & - & 0,85 & 3,61 & 2,32 \\
\hline 4 & 3,56 & 4,38 & 3,97 & 4,61 & 4,64 & - & 1,18 & 4,64 & 6,44 \\
\hline 5 & 4,53 & 5,42 & 5,07 & 5,68 & 5,75 & 0,00 & 2,95 & 5,75 & 3,08 \\
\hline 6 & 5,80 & 6,72 & 7,02 & 6,98 & 7,10 & 0,03 & 3,18 & 7,10 & 6,94 \\
\hline 7 & 7,59 & 8,51 & 9,01 & 8,79 & 8,98 & 0,15 & 6,32 & 8,98 & 8,35 \\
\hline 8 & 10,43 & 11,06 & 11,57 & 11,33 & 11,55 & 1,30 & 10,24 & 11,55 & 11,12 \\
\hline 9 & 16,34 & 16,11 & 16,75 & 16,18 & 16,36 & 11,23 & 21,12 & 16,36 & 16,89 \\
\hline 10 & 46,10 & 40,73 & 41,72 & 38,92 & 38,07 & 87,29 & 53,26 & 38,07 & 42,80 \\
\hline 9,1 & 2,20 & 2,09 & 2,17 & 2,06 & 2,05 & 2,79 & 3,36 & 2,05 & 2,04 \\
\hline 9,2 & 2,41 & 2,23 & 2,31 & 2,18 & 2,16 & 3,50 & 2,87 & 2,16 & 1,28 \\
\hline 9,3 & 2,61 & 2,39 & 2,44 & 2,33 & 2,31 & 3,43 & 3,24 & 2,31 & 4,71 \\
\hline 9,4 & 2,86 & 2,59 & 2,65 & 2,51 & 2,48 & 4,50 & 4,06 & 2,48 & 3,10 \\
\hline 9,5 & 3,25 & 2,87 & 2,93 & 2,74 & 2,68 & 6,04 & 5,03 & 2,68 & 2,58 \\
\hline 9,6 & 3,64 & 3,25 & 3,32 & 3,13 & 3,07 & 6,26 & 4,89 & 3,07 & 3,77 \\
\hline 9,7 & 4,22 & 3,75 & 3,83 & 3,60 & 3,53 & 7,50 & 6,63 & 3,53 & 4,45 \\
\hline 9,8 & 5,01 & 4,38 & 4,48 & 4,15 & 4,05 & 10,36 & 5,68 & 4,05 & 4,17 \\
\hline 9,9 & 6,76 & 5,84 & 5,98 & 5,51 & 5,34 & 14,58 & 7,92 & 5,34 & 6,43 \\
\hline 10,0 & 13,14 & 11,35 & 11,62 & 10,71 & 10,39 & 28,34 & 9,59 & 10,39 & 10,26 \\
\hline $\begin{array}{l}\text { Subtotal } \\
\text { (último décimo) }\end{array}$ & 46,10 & 40,73 & 41,72 & 38,92 & 38,07 & 87,29 & 53,26 & 38,07 & 42,80 \\
\hline Total & 100,00 & 100,00 & 100,00 & 100,00 & 100,00 & 100,00 & 100,00 & 100,00 & 100,00 \\
\hline
\end{tabular}

COFINS = Contribuições sobre o Faturamento; CPMF = Contribuição Provisória sobre Movimentação Financeira; ICMS = Imposto sobre Circulação de Mercadorias e Prestação de Serviços;

IPI = Imposto sobre Produtos Industrializados; IRPF = Imposto de Renda Pessoa Física;

IPVA = Imposto sobre a Propriedade de Veículos Automotores; ISS = Imposto sobre Serviços de Qualquer Natureza; IPTU = Imposto sobre a Propriedade Predial e Territorial Urbana.

Fonte: elaboração própria, com base em dados da Pesquisa de Orçamentos Familiares (POF/IBGE 2002-2003), do Sistema de Informações sobre Orçamentos Públicos em Saúde (SIOPS).

cional à sua renda. Entretanto, os resultados indicam que se trata de um tributo ligeiramente regressivo, o que pode ser explicado pelo componente indireto do tributo. Ela penaliza os $3 \underline{\text { o, }}$ 4o, 5ㅁ, 6o, 7o e 8 o decis (tributando-os mais que proporcionalmente à sua renda), mas é proporcional à renda no 9o decil e menos do que proporcional à renda no último decil mais rico, tendo em vista que, detendo $46,1 \%$ da renda, aporta apenas $41,7 \%$ do pagamento desse imposto. Dessa forma, o imposto é progressivo pela redistributividade que ocasiona das classes de renda média para as classes de baixa renda, mas é regressivo se comparado o seu ônus nas classes de renda média e a classe de alta renda.

Em relação ao IPTU, não é possível apontar, com base nos dados analisados, uma ten- dência clara à progressividade: o décimo mais pobre paga mais do que proporcionalmente à sua renda; entretanto, observa-se uma progressividade do imposto quando comparadas as concentrações de pagamentos e renda da classe média (4o, 6o, 7o e 8o décimos) em relação às dos $2 \underline{0}$ e $3 \underline{0}$ decis. No caso desse imposto, observa-se, em relação ao 9o decil, uma proporcionalidade à renda, e o 50 o décimo concentra um pagamento de IPTU inferior à renda que detém.

\section{Discussão}

Este artigo analisou o grau de progressividade do financiamento do SUS, isto é, se ele penali- 
za mais do que proporcionalmente aqueles com maior nível de renda ou não - ou seja, se o ônus do financiamento do setor saúde é inversamente proporcional à renda das pessoas ou não.

Para qualquer análise dos resultados desta pesquisa deve-se ter presentes duas considerações básicas. A primeira diz respeito à enorme concentração de renda da sociedade brasileira, cujo índice de Gini é de 0,57 . Assim, $80 \%$ da população mais pobre do nosso país concentram apenas $37,6 \%$ da renda, quando os $3 \%$ mais ricos concentram $25 \%$ da renda nacional.

O financiamento do SUS é realizado via pagamento de impostos e contribuições sociais, de forma que o grau de eqüidade no financiamento do sistema público de saúde é o mesmo dos tributos que o financiam. Os resultados mostraram que os decis inferiores de renda contribuem menos que proporcionalmente à sua renda, o que indicaria uma estrutura tributária progressiva, mas que, como o último décimo, que concentra $46 \%$ da renda, contribui com pouco menos do que concentra em renda, o grau de progressividade dos tributos que financiam o SUS diminui.

O ICMS é um tributo indireto, que incide sobre o valor dos bens e serviços comercializados e, como as classes de menor renda utilizam a renda preponderantemente em gasto concernente ao consumo, têm maior parcela dessa renda absorvida pelo pagamento desse tributo, diferentemente das classes mais abastadas, tornando o ICMS o mais regressivo dos tributos considerados nesta pesquisa.

Diferentemente, o IRPF, que é um imposto direto, é progressivo. Como existe uma tabela com alíquotas de pagamento diferenciadas pela renda tributável e, tendo em vista a enorme concentração de renda da sociedade brasileira, é o décimo mais rico que paga IRPF mais do que proporcionalmente à sua renda. Entretanto, este grau de progressividade é muito menor que o grau de concentração da renda da sociedade brasileira. Por este motivo, a atual discussão no Congresso Nacional acerca do aumento do número de classes de renda para cálculo do IRPF devido necessita ser fortemente encorajada pelo governo e pela sociedade brasileira, promovendo um aumento do grau de progressividade desse tributo que ainda está muito aquém do que se espera de uma proposta orientada pela justiça social.

Foi, ainda, calculado o índice de Kakwani do financiamento do SUS, desenvolvido em Kakwani 14, que sintetiza o grau de progressividade de um sistema tributário. Os dados da POF/IBGE 2002-2003 mostram o índice de Kakwani do financiamento público $(-0,008)$. O financiamento do SUS corresponde a um sistema quase proporcional, que onera proporcionalmente à renda. Em uma sociedade com o grau de desigualdade da brasileira, que exibe um índice de Gini de 0,57 , ter um financiamento do SUS proporcional é fortemente questionável sob a ótica da justiça social: ao contrário, seria necessário construir bases de financiamento do SUS - ou seja, um sistema tributário que fosse francamente progressivo, de forma a contra-restar a fortíssima concentração de renda da nossa sociedade.

Por outro lado, deve-se ter presente que, quando os estados participarem com a porcentagem de suas receitas que é estabelecida pela Emenda Constitucional n. 29, o ICMS passará a ter um peso muito maior no financiamento setorial, sendo que ele é o mais regressivo dos tributos, como já mencionado.

Dessa forma, é evidente que uma reforma tributária deve ser norteada, fundamentalmente, pela reforma e/ou criação de tributos fortemente progressivos, isto é, que onerem mais do que proporcionalmente as classes que mais renda têm.

A discussão do financiamento do SUS deve ser feita dentro do debate de financiamento da seguridade social e deve remeter à forma como está sendo tratado o ajuste macroeconômico. É necessário, de uma parte, resgatar o espírito com que foi construído o nosso sistema de seguridade social, pautado pelos princípios de um Estado de Bem-estar: a instituição do acesso universal à saúde, enquanto um direito inerente à cidadania, foi coerentemente acompanhada da inserção do setor saúde no Sistema de Seguridade Social e, ainda, do financiamento setorial por meio do OSS e dos Tesouros Federal, Estaduais e Municipais.

Entretanto, a construção desse conjunto de políticas sociais pautadas pelos princípios de um Estado de Bem-estar e de um sistema redistributivo foi se desvirtuando progressivamente. De uma parte, estabeleceu-se uma vinculação de recursos: das contribuições sobre folha de salários para a previdência e da CPMF para a saúde (que hoje também financia a previdência social). Esta vinculação havia sido propositalmente evitada no texto constitucional, para que fosse possível financiar as políticas sociais de acordo com as necessidades apresentadas pela sociedade brasileira, e não de acordo com orçamentos "engessados" e fragmentados.

De outra parte, não se prosseguiu, na reforma tributária abortada, com a criação de um sistema tributário mais progressivo: a criação da CSLL, que é um tributo direto e, a princípio, 
progressivo, não foi acompanhada da reforma dos impostos já existentes, no sentido de dotálos de maior progressividade. Isto é evidenciado pelos resultados desta pesquisa.

Ademais, deve-se mencionar que a provisão de políticas sociais passou, nos últimos 15 anos, a ser vista não mais como um dos principais instrumentos redistributivos do Estado numa sociedade altamente desigual como a nossa. Ao contrário, desde o início dos anos noventa, passou a ser tratada como instrumento do ajuste macroeconômico e, portanto, objeto do corte do gasto público. Note-se que essas políticas de ajuste vinculam nada menos que a metade do gasto público ao pagamento das despesas com juros, encargos e amortização das dívidas interna e externa.

Por sua vez, como mencionado em Ugá \& Marques 2, a saúde tem representado desde 2000 sempre menos de $17 \%$ do OSS e cerca de $5 \%$ da despesa total efetiva federal, com o qual é realmente questionável a eficácia de qualquer política de contenção do gasto social frente à manutenção da atual magnitude da despesa financeira da União. A DRU é uma evidência da prioridade absoluta do ajuste fiscal, em detrimento do cumprimento do dever do Estado no financiamento de políticas sociais cidadãs.

\section{Resumo}

Este artigo analisa o grau de progressividade dos tributos que financiam o Sistema Único de Saúde (SUS). Nele são identificados os principais tributos que financiam o SUS e, com base nos microdados da Pesquisa de Orçamentos Familiares 2002-2003, é inferida a distribuição do ônus do pagamento dos tributos diretos e indiretos que financiam o SUS e analisado o grau de progressividade dos mesmos. Foi, ainda, calculado o índice de Kakwani do financiamento do SUS, que sintetiza o grau de progressividade de um sistema tributário. Os dados mostraram que o índice de Kakwani do financiamento público é de -0,008 e que, portanto, o financiamento do SUS corresponde a um sistema quase proporcional, que onera proporcionalmente à renda. Em uma sociedade com o grau de desigualdade da brasileira, que exibe um indice de Gini de 0,57, ter um financiamento do SUS proporcional é fortemente questionável sob a ótica da justiça social: ao contrário, seria desejável construir bases de financiamento do SUS francamente progressivas, de forma a contra-restar a fortíssima concentração de renda da nossa sociedade.

SUS (BR); Financiamento da Saúde; Financiamento Governamental
Outro fator que tem gerado a necessidade de financiamento do setor público é a renúncia fiscal historicamente praticada pelo Estado brasileiro e particularmente aprofundada a partir dos anos noventa. Em primeiro lugar, deve-se mencionar a receita que o Estado deixa de arrecadar por meio do IR sobre pessoas físicas e jurídicas, seja através dos rendimentos considerados não-tributáveis, seja mediante as deduções de gastos privados em saúde, educação etc. que, juntos, resultaram numa renúncia fiscal de mais de $2 \%$ do PIB 1 . Outro fato altamente questionável é o pagamento, com recursos da União, de planos de saúde privados para os funcionários públicos, que também reduz a quantidade de recursos disponíveis para a saúde coletiva.

Se incluída essa renúncia fiscal na distribuição dos gastos por decil de renda, certamente o financiamento do sistema de saúde brasileiro se mostraria mais regressivo: enquanto os mais pobres, que não pagam imposto de renda, tampouco se beneficiam de qualquer dedução no seu gasto privado, mesmo aqueles que, embora de baixa renda, se situam na faixa dos declarantes do IR, não podem usufruir qualquer dedução referente a gastos em saúde, tendo em vista que estes dizem respeito, fundamentalmente, a medicamentos (não dedutíveis).

\section{Colaboradores}

Ambas as autoras participaram de todas as etapas do estudo.

\section{Agradecimentos}

Agradecemos aos seguintes profissionais que participaram da pesquisa como consultores: Carla Lourenço Tavares de Almeida (processamento estatístico dos dados), Thiago Pereira (estimativa dos gastos efetuados pelas famílias com tributos indiretos) e Eddy van Doorslaer (discussão metodológica). Este artigo é parte dos resultados do projeto realizado pela Escola Nacional de Saúde Pública Sergio Arouca, Fundação Oswaldo Cruz, com o apoio do Department for International Development (Reino Unido). 


\section{Referências}

1. Ugá MAD. Propostas de reforma do setor saúde nos marcos do ajuste macroeconômico [Tese de Doutorado]. Rio de Janeiro: Instituto de Medicina Social, Universidade do Estado do Rio de Janeiro; 1997.

2. Ugá MAD, Marques RM. O financiamento do SUS: trajetória, contexto e constrangimentos. In: Trindade N, Gerschman S, Edler F, Suárez J, organizadores. Saúde e democracia: história e perspectivas do SUS. Rio de Janeiro: Editora Fiocruz; 2005. p. 193-233.

3. Brasil. Emenda constitucional n. 29, de 13 de setembro de 2000. Diário Oficial da União 2000; 14 set.

4. Afonso JRR. Brasil, um caso à parte. In: XVI Regional Seminar of Fiscal Policy. Santiago: Instituto Latinoamericano y del Caribe de Planificación Económica y Social, Comisión Económica para América; 2004. p. 9.

5. Médici AC, Marques RM. Financiamento e desempenho das políticas sociais 1980-1991. Saúde Debate $1994 ; 42: 28-32$.

6. Mendes AN, Marques RM. O financiamento da atenção à saúde no Brasil. Pesquisa \& Debate 2001; 12:65-91.

7. Siqueira RB, Nogueira JR, Levy H. Política tributária e política social no Brasil: impacto sobre a distribuição de renda entre os domicílios. Rio de Janeiro: Fundação Konrad Adenauer no Brasil; 2003.

8. Pereira TR, Ikeda M. Custo Brasil - mensurando a cumulatividade das contribuições: uma proposta metodológica. Rio de Janeiro: Secretaria para Assuntos Fiscais/Banco Nacional de Desenvolvimento Econômico e Social; 2001. (Informe-se 27).
9. Wagtaff A. Measuring equity in health care financing: reflection on and alternatives to the WHO's fairness of financing index. Washington DC: Development Research Group and Human Development Network, World Bank; 2001.

10. Wagstaff A, van Doorslaer E. Equity in health care finance and delivery. In: Culyer A, Newhouse J, editors. North Holland handbook in health economics. Amsterdam: North-Holland; 2000. p. 180462.

11. van Doorslaer E, O'Donnell, Rannan-Eliya RP, Somanathan A, Adhikari SR, Akkazieva B, et al. Paying out-of-pocket for health care in Asia: catastrophic and poverty impact. Colombo: Equity in Asia-Pacific Health Systems; 2003. (EQUITAP Project: Working Paper, 2).

12. van Doorslaer E, Wagstaff A. Equity in the finance and delivery of the health care: an international perspective. Oxford: Oxford University Press; 1993.

13. van Doorslaer E, Wagstaff A, van der Burg $H$, Christiansen T, Citoni G, Di Biase R, et al. The redistributive effect of health care finance in twelve OECD countries. J Health Econ 1999; 18:291-313.

14. Kakwani NC. Measurement of tax progressivity: an international comparison. Economic Journal 1976; 87:71-80.

15. Médici A. Gastos com saúde nas três esferas de governo: 1980-1990. O financiamento da saúde no Brasil. Brasília: Organização Pan-Americana da Saúde; 1994. (Série Economia e Financiamento, 4).

Recebido em 16/Mai/2005

Aprovado em 19/Dez/2005 